\title{
Behaviour of Parallel Bamboo Strand Lumber under compression loading - an experimental study
}

\author{
Xin $\mathrm{Li}^{1,2}$, Mahmud Ashraf ${ }^{1,}{ }^{*}$, Haitao Li ${ }^{2,}{ }^{*}$, Xiaoyan Zheng ${ }^{2}$, Ali A.H. Ameri ${ }^{3}$, Safat Al-Deen ${ }^{3}$ \\ ${ }^{1}$ Deakin University Geelong, School of Engineering, Waurn Ponds, VIC 3216, Australia \\ ${ }^{2}$ College of Civil Engineering, Nanjing Forestry University, Nanjing 210037, China \\ ${ }^{3}$ School of Engineering and Information Technology, The University of New South Wales Canberra, ACT 2612, Australia
}

\begin{abstract}
This paper investigates the compression behaviour of 18 Parallel Bamboo Strand Lumber specimens. $25 \mathrm{~mm} \times 25 \mathrm{~mm}$ square specimens with varying heights and fibre orientations were tested. Test results indicated typical 5 -stage failure path, and a $45^{\circ}$ failure plane in all specimens when the compression load was applied parallel to the fibres. Specimen height did not affect the ultimate load carrying capacities but showed considerable influence on the initial stiffness as well as the post-ultimate loading regime. Experimental results showed that the deformation ratio and the energy absorption ratio for longer specimens were not affected by fibre orientations.
\end{abstract}

\footnotetext{
*Corresponding author: mahmud.ashraf@deakin.edu.au, haitao1982@126.com
} 


\section{Introduction}

Bamboo is an environmentally friendly construction material that is used worldwide for various types of structural applications [1-4]. As a green material, bamboo is considered as an efficient and effective carbon sink [5]. Whilst traditional timber products typically need decades between planting and harvesting, bamboo is very fast growing and can be harvested in 3-4 years from planting $[6,7]$. Its strength-to-weight ratio is reported to be higher than those for common wood, aluminium alloy, cast iron, structural steel and GFRP [8]. Nevertheless, the tubular shape and diverse diameter of natural bamboo, and low rigidity of some bamboo-based materials limit its applications in structure and construction [9].

Parallel Bamboo Strand Lumber (PBSL) is an innovative composite material manufactured from bamboo culm and adhesive. Bamboo culm is disassembled into loosened reticular fibre bundled with identical length and original fibre orientation. After dying to the specific moisture content, the fibre bundle is glued together using adhesive, and then assembled by hotpressing technique to form standard structural members. It offers enhanced strength, uniformity, dimensional consistency, processability and diversity in member sizes. It can be used as a wood substitute and is competitive with commonly used building materials, whilst offering renewable environmentally friendly characteristics [9$13]$.

Since PBSL is a new-type of composite material, relevant testing standards and criterion are not established. Previous research on PBSL as well as on laminated bamboo was primarily focused on flexural performance [14-20]. Limited research was reported on the experimental behaviour of PBSL under axial and eccentric compression as well as on analytical modelling of resulting stress-strain response [21-25].

In this paper, compression behaviour of PBSL with multiple configurations under compression tests are investigated. Three different heights for square specimens were used in the current study to observe variation, if any, in compressive response due to fibre length and orientations. Obtained experimental results were analysed to identify any common trend in load-deformation behaviour. Section 3 presents the results and discussions in terms of failure mechanism, load carrying capacity, deformation capacity and energy absorption ability, whilst the final section summarises the main conclusions from this research.

\section{Experimental methodology}

\subsection{Material}

Materials used in this study were manufactured from commercial PBSL columns with an average density of $1260 \mathrm{~kg} / \mathrm{m}^{3}$. All specimens were cut into a $25 \mathrm{~mm}$ square cross section with varying height ranging from $25 \mathrm{~mm}$ to $100 \mathrm{~mm}$ as illustrated in Fig. 1. The manufacturing tolerance was controlled within $\pm 1 \mathrm{~mm}$. Since PBSL is an anisotropic material, where fibre orientation could play a significant role on mechanical properties, specimens were classified into two subgroups such as parallel to the fibre (PL) and perpendicular to the fibre (PR). For each type, three specimens were tested to justify reliability of the obtained results.

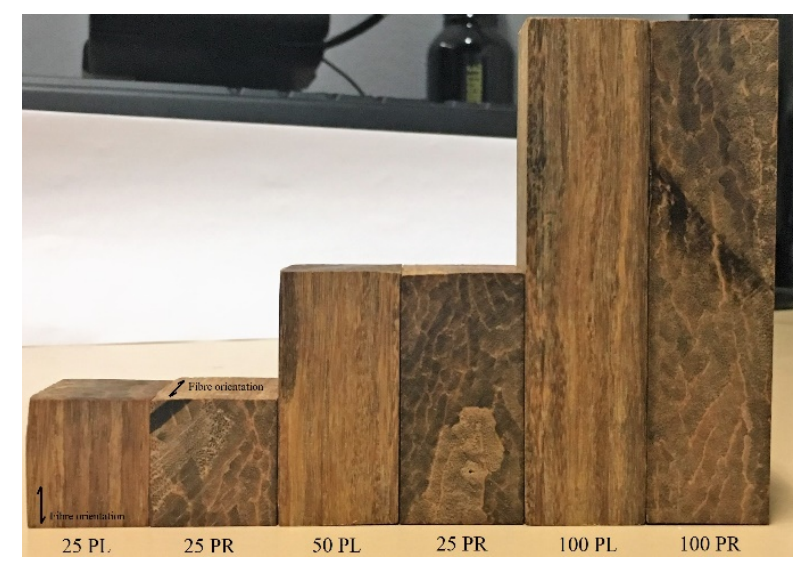

Fig. 1. Bamboo specimens used for compression tests $-25 \mathrm{~mm}$, $50 \mathrm{~mm}$ and $100 \mathrm{~mm}$ height

\subsection{Test setup}

A SHIMADZU $100 \mathrm{kN}$ universal testing machine was used for testing of the bamboo specimens. As there is no standard procedure for testing bamboo specimens, the loading procedure was taken according to ASTM D143 [26]. To ensure uniformity in rate of deformation, different loading rates were used based on the height of specimens as shown in Table 1. Designation for specimens adopted in the current study represent material name (PBSL) - height of specimen - fibre orientation (PL/PR). $100 \mathrm{~mm}$ specimens were designed as contrasting specimens according to ASTM D143 [26]. Deformation was captured by using camera for monitoring the variation between labels at each end. The setup used for compression test is shown in Fig. 2.

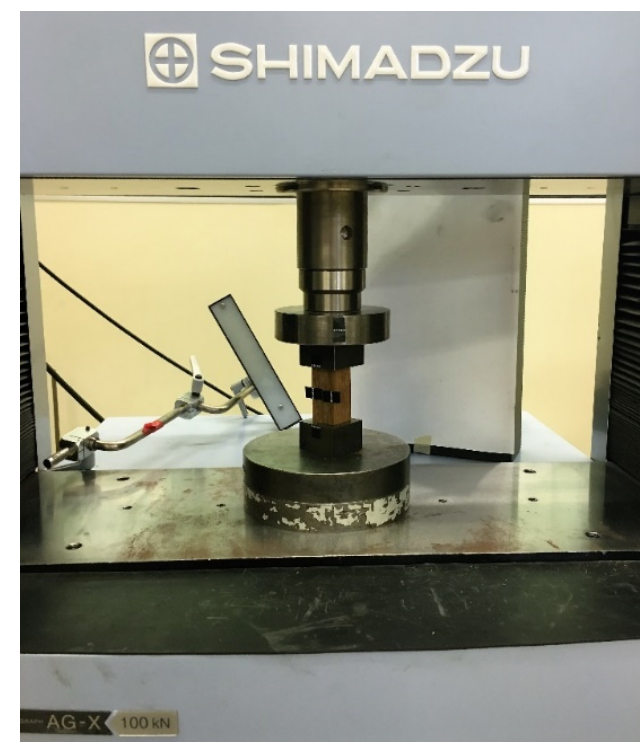

Fig. 2. Test set-up used for compression 
Table 1. Details of specimens for quasi-static testing

\begin{tabular}{lcccc}
\hline $\begin{array}{c}\text { Specimen } \\
\text { Designation }\end{array}$ & $\begin{array}{c}\text { Geometric } \\
\text { Dimensions }(\mathrm{mm})\end{array}$ & $\begin{array}{c}\text { Number of } \\
\text { Specimen }\end{array}$ & $\begin{array}{c}\text { Fibre } \\
\text { Orientation }\end{array}$ & $\begin{array}{c}\text { Loading } \\
\text { Rate } \\
(\mathrm{mm} / \mathrm{min})\end{array}$ \\
\hline PBSL 25 PL & $25 \times 25 \times 25$ & 3 & PL & 0.25 \\
PBSL 25 PR & & 3 & PR & 0.25 \\
PBSL 50 PL & $25 \times 25 \times 50$ & 3 & PL & 0.50 \\
PBSL 50 PR & \multirow{2}{*}{$25 \times 25 \times 100$} & 3 & PR & 0.50 \\
PBSL 100 PL & 3 & PL & 1.00 \\
PBSL 100 PR & & $3 R$ & 1.00 \\
\hline
\end{tabular}

\section{Results and discussion}

\subsection{Failure mechanism}

\subsubsection{Failure mode}

Typical stress-strain curves obtained from compression testing are shown in Fig. 3-5 (a). Relevant images captured by camera correspond to the onset of loading, the propagation of cracks due to gradual increase in loading, and the end of test as shown in Fig. 3-5 (b) and (c). All loading histories exhibit similar tendency up to the ultimate load, while distinct differences are obvious after the onset of failure, especially for PL specimens.

For PL specimens, in which load was applied parallel to the grains, failure triggered due to local bending and dislocation of bamboo culms. This dislocation propagated along a $45^{\circ}$ plane, as illustrated in Fig. 3-5 (b); audible splitting sound was heard once the force exceeded the ultimate capacity. At the end of plastic plateau, the bent area crossed the overall width and the test specimen buckled causing collapse of the cross-section, after which descending began. The descending process in $100 \mathrm{~mm}$ specimens occurred smoothly and rapidly until reaching the residual strength stage at about $29.5 \% P_{u}$, where $P_{u}$ is the ultimate compression load. $50 \mathrm{~mm}$ specimens showed some fluctuations in load reduction but stabilized at round $30.8 \% P_{u}$. However, it is worth noting that the descending process in $25 \mathrm{~mm}$ specimens took a distinctly different path; once the load reduced to almost $50 \%$ of $P_{u}$, a roughly linear increase was observed in load carrying capacity up to about $91.2 \% P_{u}$ before the load finally dropped again. With the decreasing height of specimens i.e. height changed from $100 \mathrm{~mm}$ to $25 \mathrm{~mm}$, the load carrying capacity gradually increased but their initial stiffness somewhat decreased as shown in Fig. 6. Importantly, all specimens failed showing considerable ductility.

For PR specimens, in which loading was applied perpendicular to the grains, failure began with the occurrence of cracks at side of the support. The main cracks expanded continuously until reaching the bearing capacity; the crack formation initiated the separation between bamboo culm and adhesive. At the end of test, specimen separated into pieces. Similar to PL specimens, the initial stiffness declined continually (Fig. 6) and the descent phase flattened out gradually for shorter specimens, until reaching their residual strength at about $25.5 \% P_{u}, 30.8 \% P_{u}$, and $46.1 \% P_{u}$ respectively. It is also worth noting that the loading period and axial displacements were larger than the corresponding PL specimens, especially in $25 \mathrm{~mm}$ specimens. All specimens showed considerable ductility prior to failure.

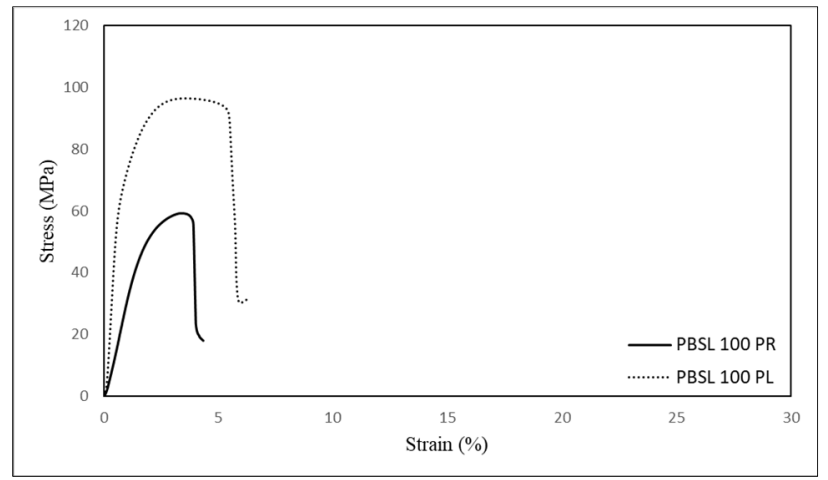

(a) Stress-strain curves for $100 \mathrm{~mm}$ specimens
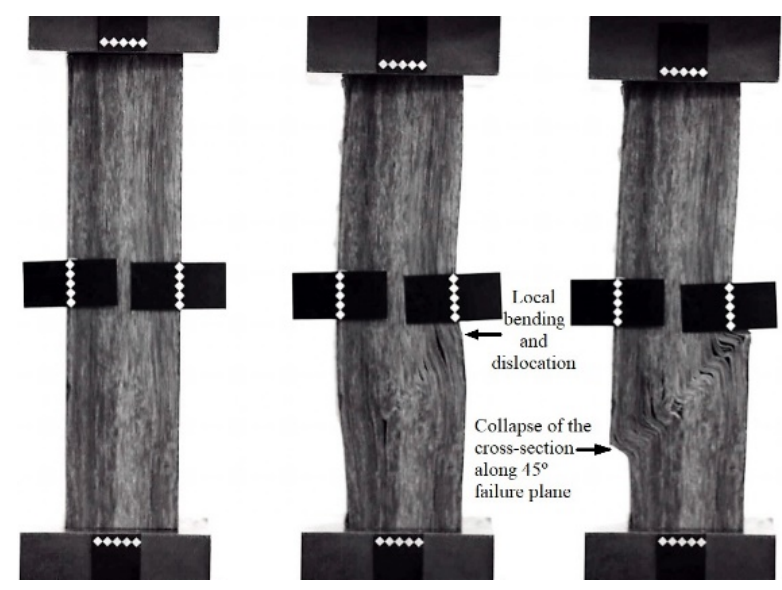

(b) Failure characteristics of PL specimens

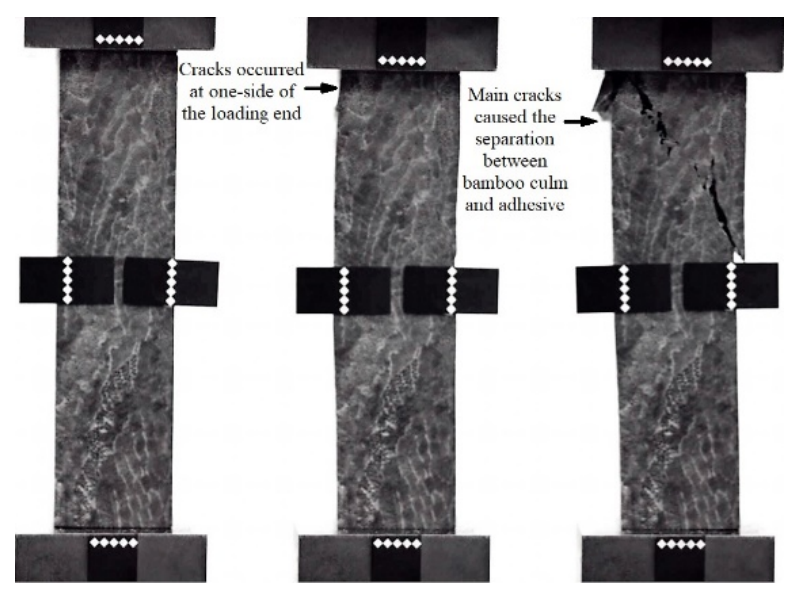

(c) Failure characteristics of PR specimens

Fig. 3. Load-deformation behaviour and failure characteristics of $100 \mathrm{~mm}$ specimens 


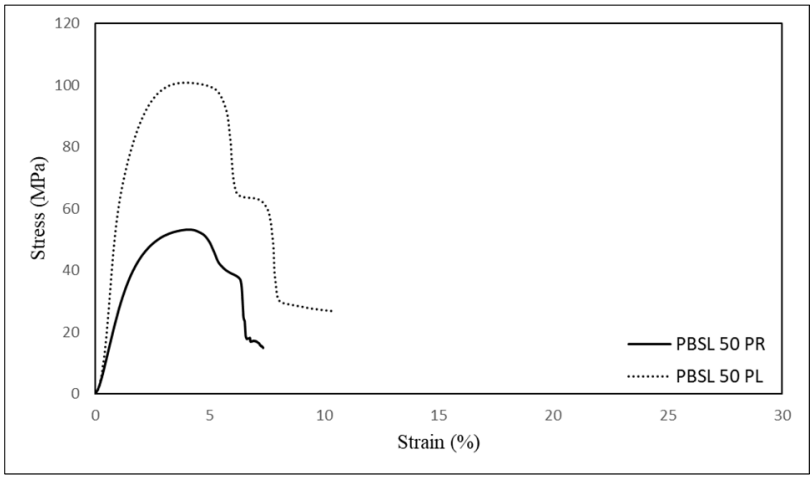

(a) Stress-strain curves for $50 \mathrm{~mm}$ specimens

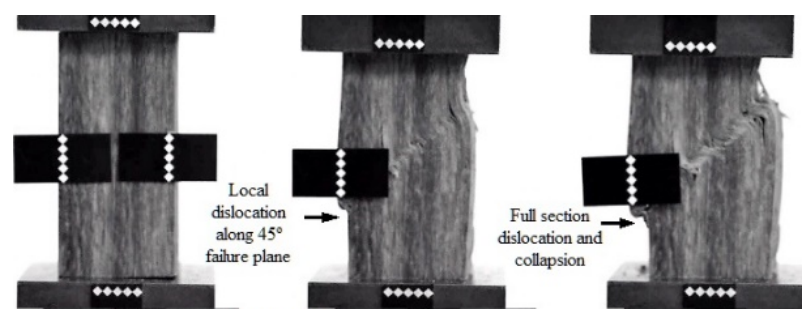

(b) Failure procedures of PL specimens

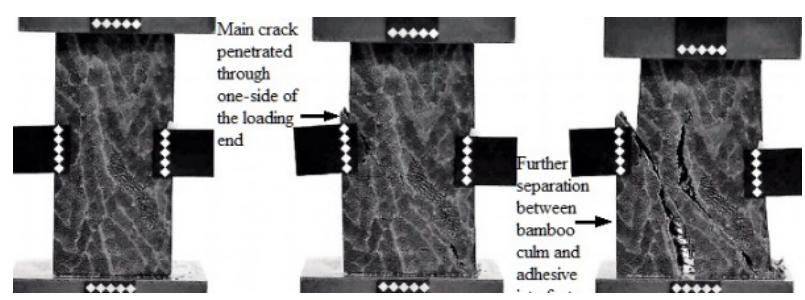

(c) Failure characteristics of PR specimens

Fig. 4. Load-deformation behaviour and failure characteristics of $50 \mathrm{~mm}$ specimens

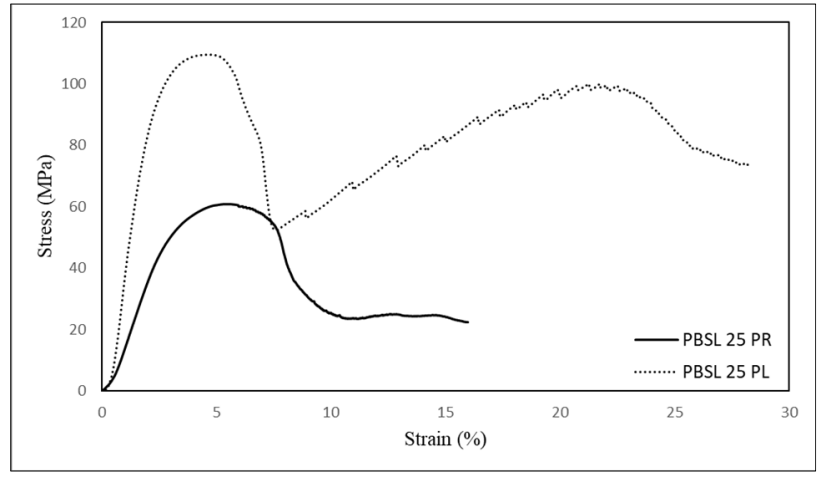

(a) Stress-strain curves for $25 \mathrm{~mm}$ specimens

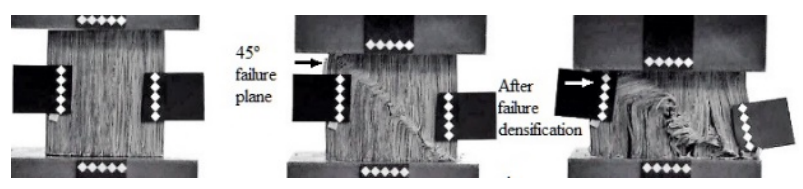

(b) Failure characteristics of PL specimens

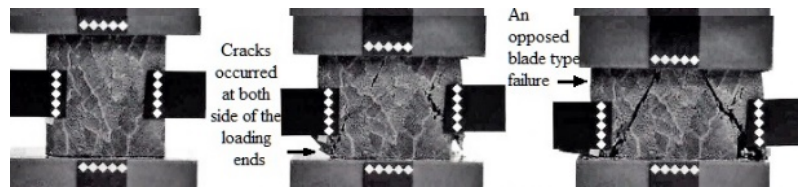

(c) Failure characteristics of PR specimens

Fig. 5. Load-deformation behaviour and failure characteristics of $25 \mathrm{~mm}$ specimens

\subsubsection{Failure influenced region}

Once the mechanical tests were complete, failure influenced region in each specimen was carefully investigated to identify important failure characteristics.

Results from PL specimens indicated that complete bending and dislocation occurred within a specific area; approximately $25 \mathrm{~mm}$ along the height of specimen. This may correspond to the $25 \mathrm{~mm}$ cross-section in this study with a failure plane of 45 degree, as shown in Fig. 3-5 (b). Considering the specific specimen configuration in 25 $\mathrm{mm}$ height specimens, when the whole cross-section failed, all fibres were condensed and packed together to resist additional loading; this is usually defined as densification or stacking effect. Similar fluctuation during descending stage could also be seen in $50 \mathrm{~mm} \mathrm{PL}$ specimens as the limited support area, more or less, affected by the condensation of bamboo fibres at ends.

In PR specimens, longer samples showed larger influenced regions. Main cracks extended from edge towards the centre of the height, as shown in Fig. 3-4 (b). However, main cracks in $25 \mathrm{~mm}$ specimens showed crack propagation along the height of the specimen; cracks penetrated through the section as illustrated in Fig. 5 (b); Thus, large-proportion separations between bamboo culms and adhesive, in shorter specimens, counterbalanced the densification effects but contributing to a better ductility after failure. 


\subsubsection{Failure procedure}

Fig. 6 shows stress-strain behaviours of all tested specimens, and it is observed, herein, that typical failure procedure of PBSL under compression tests can be divided into 5 stages: During the initial loading stage, each test showed an elastic behaviour up to a specific load, followed by a nonlinear behaviour until the ultimate load was reached, after which a plastic plateau was observed. The load drops gradually when descending commenced, before residual strength approximately tends to be stable. These observations are in accordance with previously reported research on PBSL [9, 19, 25].

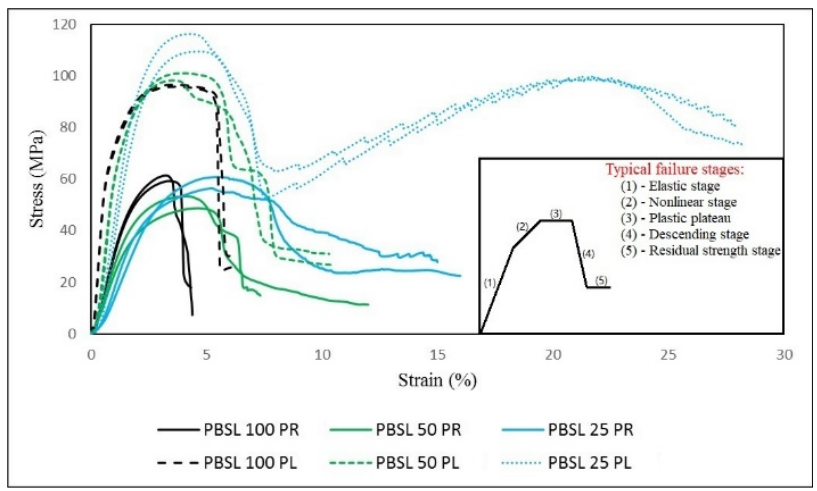

Fig. 6. Stress-strain behaviours of PBSL under compression tests

\subsection{Data analysis}

Table 2 shows key test results recorded for $25 \mathrm{~mm}, 50$ $\mathrm{mm}$ and $100 \mathrm{~mm}$ specimens. It is worth noting that specific geometric dimensions and fibre orientation not only influenced the failure mechanism, as discussed in the previous section, but also showed clear effects on load carrying capacity, deformability and energy absorption capacity of the specimens.

Table 2. Details of quasi-static tests results

\begin{tabular}{cccccc}
\hline $\begin{array}{c}\text { Specimen } \\
\text { Designation }\end{array}$ & $\begin{array}{c}\text { Maximum } \\
\text { Force } \\
(\mathrm{kN})\end{array}$ & $\begin{array}{c}\text { Maximum } \\
\text { Stres } \\
(\mathrm{MPa})\end{array}$ & Strain & $\begin{array}{c}\text { Energy } \\
\text { Absorption } \\
(\mathrm{J})\end{array}$ & $\begin{array}{c}\text { Unit Energy } \\
\text { Absorption } \\
\left(\mathrm{J} / \mathrm{mm}^{3} \boldsymbol{e}^{-6}\right)\end{array}$ \\
\hline PBSL 25 PL-1 & 65.58 & 104.93 & 0.056 & 63.25 & 4048.00 \\
PBSL 25 PL-2 & 70.54 & 112.86 & 0.052 & 62.36 & 3991.04 \\
PBSL 25 PL-3 & 68.29 & 109.26 & 0.062 & 70.84 & 4533.76 \\
PBSL 25 PR-1 & 35.99 & 57.58 & 0.083 & 53.01 & 3392.64 \\
PBSL 25 PR-2 & 35.70 & 57.12 & 0.062 & 37.76 & 2416.64 \\
PBSL 25 PR-3 & 37.99 & 60.78 & 0.063 & 38.74 & 2479.36 \\
PBSL 50 PL-1 & 54.53 & 87.25 & 0.059 & 132.17 & 4229.44 \\
PBSL 50 PL-2 & 59.45 & 95.12 & 0.039 & 83.66 & 2677.12 \\
PBSL 50 PL-3 & 60.81 & 97.30 & 0.045 & 100.91 & 3229.12 \\
PBSL 50 PR-1 & 33.82 & 54.11 & 0.045 & 54.32 & 1738.24 \\
PBSL 50 PR-2 & 32.26 & 51.62 & 0.044 & 48.83 & 1562.56 \\
PBSL 50 PR-3 & 32.25 & 51.60 & 0.055 & 57.84 & 1850.88 \\
PBSL 100 PL-1 & 52.96 & 84.74 & 0.032 & 170.60 & 2729.60 \\
PBSL 100 PL-2 & 58.70 & 93.92 & 0.039 & 182.01 & 2912.16 \\
PBSL 100 PL-3 & 58.26 & 93.22 & 0.039 & 180.89 & 2894.24 \\
PBSL 100 PR-1 & 35.87 & 57.39 & 0.043 & 104.19 & 1667.04 \\
PBSL 100 PR-2 & 37.10 & 59.36 & 0.035 & 85.57 & 1369.12 \\
PBSL 100 PR-3 & 36.97 & 59.15 & 0.037 & 91.42 & 1462.72 \\
\hline
\end{tabular}

\subsubsection{Load carrying capacity}

Size effect shows a negligible influence on load-carrying capacity for PR specimens as shown in Fig. 7. The mean ultimate stress in perpendicular to the grain was $56.5 \mathrm{MPa}$ with a coefficient of variation (COV) of 0.06. In PL specimens, shorter specimens produced considerably higher mean stress values due to the observed densification effect; especially $25 \mathrm{~mm}$ specimens produced a mean ultimate stress of 109.02 $\mathrm{MPa}$. PBSL is a known anisotropic material and previous studies indicated that PR/PL strength ratio was around 0.6. In this study, the PR/PL ratio varied between 0.54 and 0.65 ; this variation was primarily due to the size effect. The mean strength ratio is taken as 0.58 , which is in line with the previous studies.

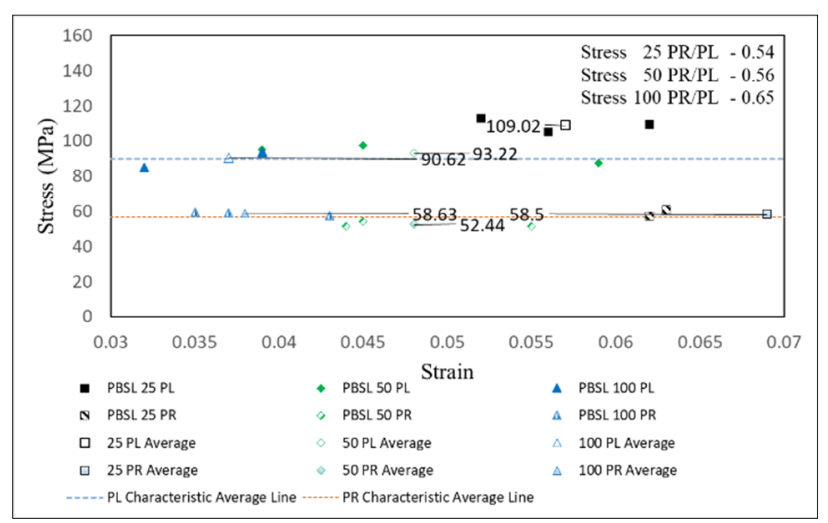

Fig. 7. Comparative stress analysis for PBSL specimens

\subsubsection{Deformation capacity}

Size effect showed a significant influence on specimen deformations. Strain at ultimate stress increased from 0.037 to 0.069 as the specimen height was reduced from $100 \mathrm{~mm}$ to $25 \mathrm{~mm}$. In terms of fibre orientation, PR specimens always deformed more than similar PL specimens as shown in Fig. 8. Differences in strain at ultimate stress for PR and PL specimens were negligible for both $50 \mathrm{~mm}$ and $100 \mathrm{~mm}$ specimens with a PR/PL ratio of 1.01 and 1.05 respectively, while those for $25 \mathrm{~mm}$ specimens was around $22 \%$. That is, the failure procedure makes the shorter specimen more sensitive to deformation, but the deformation ratio of higher specimen tended to be stable irrespective of fibre orientations.

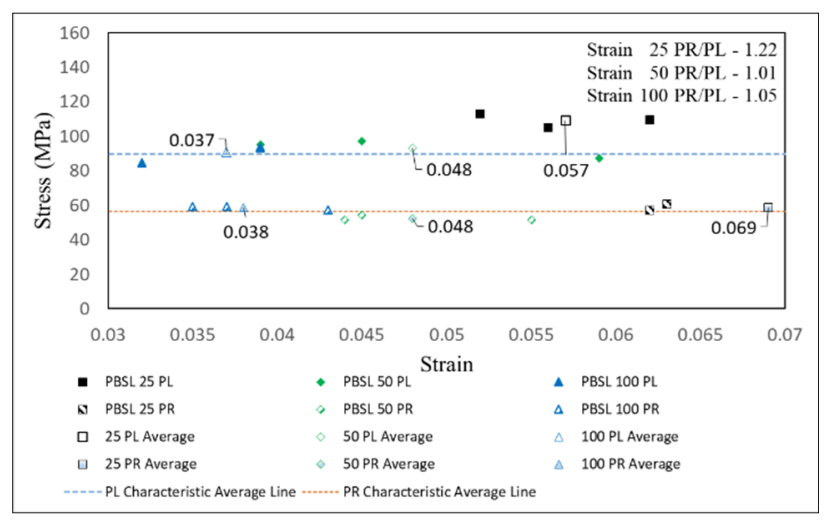

Fig. 8. Strain analysis for the tested PBSL specimens 


\subsubsection{Energy Absorption}

Size effect showed a significant influence on energy absorption capacities. As shown in Table 2, larger specimens absorbed more energy during the whole loading procedure due to their larger volume, whilst Fig. 9 shows unit energy absorption capacity. The numbers in Fig. 7 are the average energy of each specimen designation. Whilst some variation was observed in energy absorption capacities, the common trends were as follows:

- Shorter specimens absorbed more energy, which may be contributed partly to the densification effects observed for $25 \mathrm{~mm}$ specimens.

- PL specimens always showed more energy absorption capabilities when compared against their PR counterparts.

This is consistent with our previous analysis about densification effects in shorter specimens. In terms of fibre orientation, PL specimens had much better performance on energy absorption. Meanwhile, similar $\mathrm{PR} / \mathrm{PL}$ ratios were observed in both $50 \mathrm{~mm}$ and $100 \mathrm{~mm}$ specimens which indicated the energy absorption ratio of higher specimen tended to be stable between fibre orientations.

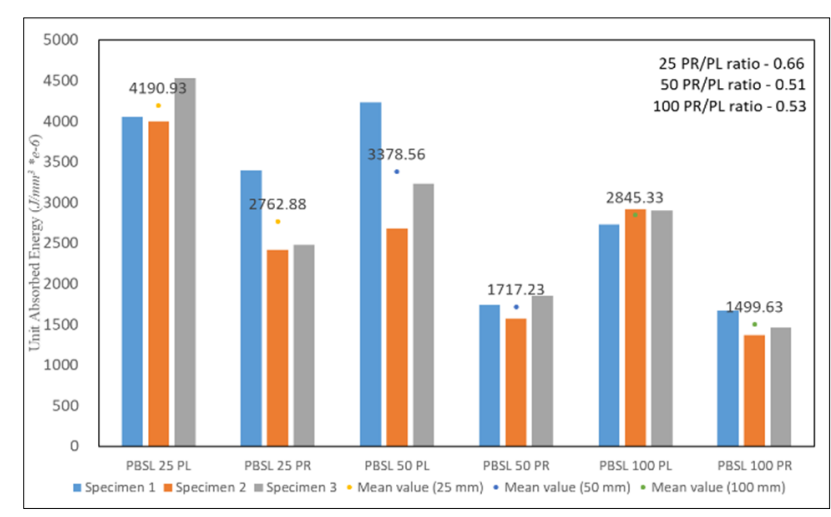

Fig. 9. Energy absorbed by the tested specimens

\section{Conclusion}

This paper presented an experimental investigation on the deformation and failure mechanism of PBSL specimens subjected to compression loading. Tests were conducted on square specimens with different heights to achieve a clear insight into failure characteristics. Fibre orientation was carefully considered as this has been reported to be a major factor in natural fibrous materials such as timber and bamboo. A typical 5-stage failure path was observed for all tested specimens, which was highly affected by the overall height of the specimens. Densification effects observed for $25 \mathrm{~mm}$ specimens, especially for PL directions, resulted in considerable changes in the postultimate loading pattern. The deformation capacity and energy absorption ratio for longer specimens were not highly affected by fibre orientations. However, further experimental and numerical studies are required to have a clear understanding of PBSL under compression and to subsequently develop design rules for practical applications.

\section{Acknowledgement}

The authors gratefully acknowledge Paul J. Hazell, Hongxu Wang, Zongjun Li and others from UNSW Canberra, Nanjing Forestry University and Deakin University for assisting on this work.

\section{References}

1. E.A. Nurdiah., The potential of bamboo as building material in organic shaped buildings, ProcediaSocial and Behavioural Sciences 216 (2016): 30-38.

2. D.L. Jayanetti, and P.R. Follett., Bamboo in construction in Modern Bamboo Structures. CRC Press, (2008). 35-44.

3. P. Van der Lugt, A.A.J.F. Van den Dobbelsteen, and J.J.A. Janssen., An environmental, economic and practical assessment of bamboo as a building material for supporting structures. Construction and Building Materials 20.9 (2006): 648-656.

4. J.J.A. Janssen., Designing and building with bamboo. International Network for Bamboo and Rattan, (2000).

5. JQ Yuen, T Fung, and A.D. Ziegler., Carbon stocks in bamboo ecosystems worldwide: Estimates and uncertainties. Forest Ecology and Management 393 (2017): 113-138.

6. S.C. Lakkad, and J.M. Patel., Mechanical properties of bamboo, a natural composite. Fibre science and technology 14.4 (1981): 319-322.

7. S. Amada, et al., Fiber texture and mechanical graded structure of bamboo. Composites Part B: Engineering 28.1-2 (1997): 13-20.

8. M. Mahdavi, P.L. Clouston, and S.R. Arwade., Development of Laminated Bamboo Lumber: Review of Processing, Performance, and Economical Considerations. Journal of Materials in Civil Engineering 23.7 (2010): 1036-1042.

9. H Li, et al., Compressive performance of laminated bamboo. Composites Part B: Engineering 54 (2013): 319-328.

10. J.F. Correal, and L.F. Lopez., Mechanical properties of Colombian glued laminated bamboo. Mechanical properties of Colombian glued laminated bamboo. Taylor \& Francis, London, UK, (2008).

11. L.F. Lopez, and J.F. Correal., Exploratory study of the glued laminated bamboo Guadua angustifolia as a structural material. Ciencia y Technologia $\mathbf{1 1 . 3}$ (2009): 171-182.

12. N. Nugroho, and N. Ando., Development of structural composite products made from bamboo II: fundamental properties of laminated bamboo lumber. Journal of wood science 47.3 (2001): 237.

13. C.S. Verma, and V.M. Chariar., Development of layered laminate bamboo composite and their 
mechanical properties. Composites Part B: Engineering 43.3 (2012): 1063-1069.

14. Y Wei, X.W. Wang, and G.F. Li., Mechanical properties test of bamboo scrimber flexural specimens reinforced with bars. Acta Materiae Compositae Sinica 4 (2014): 024.

15. G Chen, et al., Experimental evaluation on mechanical performance of OSB webbed parallel strand bamboo I-joist with holes in the web. Construction and Building Materials 101 (2015): 9198.

16. Y Li, et al., Bending resistance of I-section bamboosteel composite beams utilizing adhesive bonding. Thin-walled structures 89 (2015): 17-24.

17. H Li, et al., Flexural performance of laminated bamboo lumber Beam. BioResources 11.1 (2015): 929-943.

18. Y Wei, et al., Theoretical Analysis and Experimental Test of Full-scale Bamboo Scrimber Flexural Components. Journal of Civil, Architectural \& Environmental Engineering 34 (2012): 140-145.

19. $\mathrm{H} \mathrm{Li}$, et al., Experimental study on mechanical performance of side pressure laminated bamboo beam. Journal of Building Structures 36.3 (2015): 121-126.

20. H Zhang, et al., AFRP Influence on Parallel Bamboo Strand Lumber Beams. Sensors 18.9 (2018): 2854.

21. J Su, et al., Experimental research on parallel bamboo strand lumber column under axial compression. China Sciencepaper 10.1 (2015): 39-41.

22. $\mathrm{H} \mathrm{Li}$, et al., Mechanical evaluation for laminated bamboo lumber along two eccentric compression directions. Journal of wood science $\mathbf{6 2 . 6}$ (2016): 503517.

23. $\mathrm{H} \mathrm{Li}$, et al., Mechanical properties of laminated bamboo lumber column under radial eccentric compression. Construction and Building Materials 121 (2016): 644-652.

24. $\mathrm{H} \mathrm{Li}$, et al., Eccentric Compression Performance of Parallel Bamboo Strand Lumber Columns. BioResources 10.4 (2015): 7065-7080.

25. $\mathrm{H} \mathrm{Li}$, et al., Mechanical performance of laminated bamboo column under axial compression. Composites part B: engineering 79 (2015): 374-382.

26. Standard, ASTM. "D143-14, Standard methods of Testing Small Clear Specimens of Timber, ASTM International, West Conshohocken, PA, 2014, DOI: 10.1520/D0143." (2014). 